\title{
ORTODOXIA Y POLÍTICAS DE AUSTERIDAD EN EUROPA
}

\section{ORTHODOXY AND AUSTERITY POLICIES IN EUROPE}

\author{
Rafael Böcker Zavaro*
}

\author{
RESUMEN
}

En este artículo se presenta una serie de perspectivas que se han ido desarrollando en el siglo xx, con el fin de analizar la dinámica del sistema capitalista. Se reflexiona sobre las diversas posturas acerca del rol asignado al mercado y al Estado. Se pretende entender la actual coyuntura de crisis global, cuyo epicentro está localizado en los países periféricos de Europa. Esto está socavando los cimientos mismos de la Unión Europea desde hace seis años.

PALABRAS CLAVE: EUROPA * POLÍTICA ECONÓMICA * DESARROLLO * ESTADO * MERCADO

\section{ABSTRACT}

This article presents several perspectives that have been developed in order to analyze the capitalism system dynamics in the twentieth century. It shows the different positions assign to the market and the state, building a useful tool to understand the current global crisis with a special focus in European peripheral countries. This is undermining the foundations of the European Union, since the last six years.

KEYWORDS: EUROPE * ECONOMIC POLICY * DEVELOPMENT * STATE * MARKET

Universitat Rovira i Virgili de España.

rafael.zavaro@gmail.com 


\section{INTRODUCCIÓN}

A partir de la segunda posguerra mundial, el desarrollo de los países subdesarrollados se convirtió en un nuevo mecanismo ordenador de las relaciones internacionales. En este contexto, el presidente norteamericano Harry S. Truman marcó objetivos y caminos para aquellos que quisieran seguir el american way of life en su famoso discurso del Estado de la Unión de 1949. No obstante, con los años quedó en evidencia que el modo de vida de los países desarrollados no podía extenderse a los subdesarrollados, en gran parte por la subordinación de unos sobre los otros, proceso que se profundizó a partir de la década de 1970, cuando el capitalismo global se orientó hacia un modelo neoliberal $y$ financiero.

Lo paradójico de ello es que los países desarrollados también fueron estableciendo sus propias jerarquías entre sí: no es lo mismo el papel de España y Chipre que el de Alemania o Francia. La conformación de la periferia europea fue clave para anclar un exitoso proceso asimétrico de integración neoliberal a favor del desarrollo de los desarrollados, esto es, de la tasa de beneficios de las grandes fortunas europeas. El neoliberalismo a lo europeo conjugó el mínimo Estado de Bienestar, útil para sostener un modelo económico-laboral-financiero dependiente de las grandes fortunas de los países centrales (Alemania como centro del centro) y tantas burbujas como fueran necesarias, para el enriquecimiento de la reducida elite económica en cada país periférico. Este esquema funcionó así las últimas tres décadas, hasta dar paso a la presente crisis y al subdesarrollo en los países desarrollados periféricos.

Por esta razón, este artículo tiene como objetivo vincular las principales perspectivas del desarrollo capitalista con el actual contexto de crisis global. El objeto de estudio son las políticas públicas impulsadas por diversos países occidentales en la historia reciente. La problemática que recorre las siguientes páginas se basa en la necesidad de reflexión sobre el rol asignado al mercado y al Estado, en tanto mecanismos de asignación y distribución de recursos, pero también pilares fundamentales para instaurar modelos socioeconómicos específicos. Ante todo, la pregunta no es si los estados deben intervenir o no en la economía, ya que los mercados no existen por sí solos, siempre existen en un contexto de reglas, leyes, regulaciones y políticas públicas. Por ello, el neoliberalismo no defiende un estado ausente, sino que instaura uno que intervenga activamente para desregular, flexibilizar el mercado laboral, privatizar y subsidiar a los sectores concentrados, pero aplicando en lo público la llamada receta ortodoxa de austeridad propia de la economía neoclásica.

\section{CAPITALISMO Y KEYNESIANISMO}

Desde su origen, el capitalismo se reinventó en cada crisis. Así sucedió también con la primera crisis de sobreproducción en la década de 1870, cuando el bienestar fue el concepto usado para un gran pacto entre todas las clases sociales en los países centrales de Europa. A partir de este momento, coincidieron la integración de los mercados internacionales de productos y de factores, así como, el aumento del proteccionismo $y$ del intervencionismo del Estado (a diferencia del abstencionismo de mediados del siglo XIX). Este proteccionismo moderado favoreció el crecimiento económico de los países entonces desarrollados (básicamente, Estados Unidos, Australia, Canadá, Francia, Dinamarca, Alemania, Italia, Japón, Noruega, Suecia $y$ Reino Unido). Primordialmente, porque el proteccionismo fue selectivo para determinadas industrias y fue acompañado por políticas económicas más intervencionistas que fomentaron el desarrollo de las industrias nacientes. Los gobiernos comenzaron a practicar una política industrial intervencionista en apoyo de las industrias nacionales.

Adicionalmente, los gobiernos dejaron también atrás el abstencionismo del Estado liberal en cuanto a la distribución de la renta; de manera que en este periodo, comenzaron a sentarse las bases del Estado del Bienestar, con el inicio de reformas tributarias progresivas, de los gastos en educación y sanidad, y el establecimiento de los primeros seguros sociales. Con estas reformas, el Estado creó las condiciones necesarias para la armonía social y para la acumulación rentable de capital. No obstante, 
se produjo una creciente militarización de las naciones que entonces se estaban industrializando, lo cual generó tensiones y guerras entre las nuevas potencias, como Alemania, Estados Unidos, Japón, Italia y Rusia, que acabarían desencadenando la Primera Guerra Mundial. Por otro lado, provocó el desplazamiento del centro hegemónico hacia la costa este de los Estados Unidos: el crecimiento económico norteamericano tuvo su base en el amplio tamaño de su mercado interno y luego, se sostuvo en la economía mundial (Comín, 2005).

En la primera parte del siglo xx, sucedieron dos guerras mundiales y la Gran Depresión de los años 30: entre 1919 y 1933 tuvo lugar un enorme descenso de los ingresos y la producción y se elevó espectacularmente el desempleo. Ello explica la razón por la cual, la mayoría de los países siguieran políticas comerciales y cambiarias opuestas a cualquier forma de cooperación. Con estas, cada país perseguía salir de la crisis, recuperar y mejorar la renta, $y$ el empleo a expensas de los demás. En el terreno monetario, este tipo de política se materializó en las devaluaciones competitivas. En el terreno comercial, consistió en elevar los aranceles, imponer cupos y en algunos casos, establecer el control de cambios, con el propósito de restringir fuertemente las importaciones.

El estancamiento económico y social durante este periodo provocó un cambio de actitud frente al libre mercado como "el orden natural" del funcionamiento de la economía. En este contexto, Keynes (1985) comenzó a convertirse en el economista más influyente del siglo xx y su nombre aún sigue ligado a las políticas económicas expansivas y en general, a todo avance de la intervención del Estado en los asuntos económicos. Si bien, el tipo de políticas públicas que Keynes defendió eran frecuentes en la década de 1930, sus teorías representaron un esfuerzo consciente por retratar los cambios profundos que modificaron al Estado y al sistema capitalista a principios del siglo xx. Así, la Teoría general de la ocupación, el interés y el dinero de Keynes, es la manifestación de una crisis en la teoría económica ortodoxa en el marco de la más grande crisis del capitalismo (Kicillof, 2008). Keynes creía que esta teoría había sido concebida para una etapa histórica del pasado. En palabras de Kicillof:

... cuando llegó el turno de lidiar con la inflación de posguerra como cuando, poco después, sobrevino la depresión, la ortodoxia defendió y pretendió aplicar - y lo hizo en muchos casoslas tradicionales políticas contractivas, encaminadas a reducir el gasto público, restringir el crédito y la liquidez, $y$ a presionar para que se produjera una reducción generalizada de los salarios. Tanto en un contexto de inflación como de alta desocupación, la contracción es la panacea de la ortodoxia, porque supone que cuando el mercado actúa por sí mismo es infalible; de modo que la respuesta consiste en evitar toda intromisión en sus mecanismos [por parte del Estado y los trabajadores organizados] (2008: 23).

En este sentido, Keynes (1985) introdujo una perspectiva dinámica en el análisis económico que le permitió tratar la inestabilidad cíclica a corto plazo de las economías desarrolladas. De este modo, sentó las bases de lo que luego serían las teorías del desarrollo económico en la postguerra (economía del desarrollo, estructuralismo latinoamericano, teorías de la dependencia...), pues rompió el esquema de la monoeconomía neoclásica y concretamente, rechazó que los agentes económicos fuesen racionales y los mercados se equilibrasen por sí solos. Incluso, no solo situó el problema económico principal en la infrautilización de recursos (desempleo y subempleo de capital físico y humano), sino que vio en la intervención estatal una solución al desequilibrio del mercado o al equilibrio ineficiente del mercado autorregulado. De este modo, las políticas económicas se elaboraron en la postguerra, como un mecanismo sistemático para corregir los fallos surgidos del libre funcionamiento de los mercados y que además, son inherentes a los ciclos económicos.

Keynes cambió completamente el punto de vista de la economía, al abandonar el estudio del comportamiento de los agentes y de los mercados, para pasar a analizar directamente las variables agregadas. Con ello rechazó el 
análisis individual, y estableció que el Estado debía gestionar el mercado, al igual que debía gestionar la demanda global. En palabras de Rojo (2006), Keynes avanzó en sus posiciones intervencionistas a lo largo de los años 30. Confiaba en la eficacia del mercado:

... para asignar los recursos a largo plazo y creía que la centralización de las decisiones sólo llevaría a mayores despilfarros; pero pensaba que el mercado había fracasado en la determinación del volumen no de la dirección del empleo efectivo y consideraba necesaria la intervención del Estado para determinar el volumen total de los recursos dedicados a aumentar el capital productivo y mantener así niveles altos de demanda y empleo (2006: 91).

La consecuencia de este análisis a partir de Keynes, fue que la intervención del Estado fue considerada fundamental. De esta manera, la intervención estatal se convirtió en un mecanismo directamente productor de relaciones sociales $y$ no un mero "racionalizador" de los costes que el modelo de desarrollo económico generó.

A pesar de la fortaleza lógica y empírica de este razonamiento, los fundamentos teóricos de Keynes fueron abandonados con los años. Lo paradójico está en que fueron los propios seguidores de Keynes, desde un principio $y$ hasta el presente, quienes sometieron a la Teoría general a un proceso de "apropiación selectiva": algunas de sus ideas fueron absorbidas por la teoría económica; en cambio, otras fueron desechadas sin ser siquiera sometidas a crítica (Kicillof, 2008).

Mientras tanto, la segunda postguerra mundial significó para el mundo grandes transformaciones:

1) Europa tuvo que contar con la ayuda de Estados Unidos y la Unión Soviética para liberarse del nazismo. En la inmediata postguerra, los problemas más urgentes no parecían situarse en el Sur, sino en el Norte: era necesaria la reconstrucción de la Europa en ruinas. Con esta finalidad se implementó el Plan Marshall, aunque también estaba diseñado para proporcionar un amplio mercado al potencial productivo norteamericano en tiempos de paz. Además, este programa de reconstrucción europea confirmó a Estados Unidos en el papel de nación líder del llamado "Mundo Libre".

2) La estrategia del gobierno norteamericano rechazó la idea de mercado autorregulado: se tenía la convicción de que los mercados mundiales podrían restablecerse y expandirse mediante su administración por parte de los gobiernos y de las grandes corporaciones. De hecho, el proceso de concentración del capital que conllevó el predominio de grandes empresas, impuso la exigencia de planificación estratégica. Ello otorgó mayor atención a las formas de organización industrial y a la expansión del comercio y la producción de la economía mundial (Arrighi, 1999).

3) Las políticas económicas keynesianas explican el aumento del crecimiento capitalista de postguerra, promoviendo la innovación industrial y la ideología industrializadora. Políticas que se financiaron por medio de la recaudación impositiva y contrariamente a lo esperado, los impuestos no frenaron la acumulación, sino que al ampliar la demanda agregada, impulsaron una mayor inversión en la economía.

Tanto el modelo fordista como el slaonista caracterizan la época de crecimiento continuado, de desarrollo industrial que define al régimen de acumulación intensivo conocido como keynesianismo-fordista. El Estado de postguerra se convirtió así en consumidor de bienes y servicios, con el fin de regular la demanda agregada y evitar las crisis cíclicas de sobreproducción inherentes a la lógica del sistema capitalista. Por otro lado, aunque redujo el proteccionismo exterior, estableció mecanismos de apoyo a la industria nacional regulando el funcionamiento de las multinacionales dentro de sus fronteras. Además, el Estado potenció: 
... la creación de empresas públicas, sobre todo en aquellos sectores que son considerados como estratégicos o que no son atendidos por la iniciativa privada. Pero no se limitan a esto las actuaciones del Estado, pues para minimizar los efectos negativos del crecimiento económico se aplican políticas de desarrollo regional $y$ ordenación territorial que pretenden paliar los costes sociales y los desequilibrios socioeconómicos y espaciales. Con estos tipos de intervenciones los poderes públicos contribuyen a garantizar los mecanismos de acumulación del modelo fordista (Méndez y Caravaca, 1996: 110).

4) En la postguerra mundial, la noción de desarrollo orientó las políticas nacionales de los países de todo el mundo y dio origen a la economía del desarrollo, constituyéndose formalmente en los años 40.

\section{ECONOMÍA DEL DESARROLLO}

El nacimiento de una subdisciplina denominada economía del desarrollo, coincidió con el período de descolonización y nació bajo la influencia del enfoque keynesiano que dominó el periodo de postguerra. Un enfoque que daba al Estado un salvoconducto teórico que le permitía un amplio campo de intervención, dada la posibilidad de que el libre juego del interés personal puede hacer que los recursos no se inviertan de forma óptima. El teorema de la mano invisible no solo enuncia que un equilibrio de competencia perfecta a largo plazo genera una asignación óptima de los recursos, siempre sujeto a la condición de que la distribución de los ingresos está dada, sino también que toda asignación óptima de los recursos es un equilibrio de competencia a largo plazo. La idea de que un sistema de competencia perfecta optimiza los recursos de la sociedad en términos de bienestar (según Pareto) es una idea sugerente y sin duda, un hito de la economía neoclásica.

Pero todo este aparataje analítico del bienestar paretiano presentaba deficiencias de gran importancia. Pronto se descubre que existen fallos en la estructura de los mercados de competencia perfecta que dan lugar a imperfecciones que impiden alcanzarla, ya sea por el poder que tienen algunas empresas sobre el mercado para fijar precios a distintos niveles competitivos o por la existencia de economías de escala significativas en algunos procesos productivos, los cuales impiden que no se produzca el equilibrio competitivo. Un problema añadido es que no solo pueden aparecer fallos en la estructura de los mercados, sino también en el comportamiento de los agentes económicos que impidan que los mercados actúen eficientemente e incluso, que los resultados que proporcionen los mercados eficientes no sean los deseados por la sociedad, ya que se consideran injustos o moralmente inaceptables. Es el caso de fallos en la estructura de los mercados ligados a externalidades: en tanto que la simple existencia de competencia no garantiza el óptimo social; el modelo general competitivo constituye una guía que permite al economista detectar los fallos del mercado y estudiar las medidas de política económica que procuran teóricamente, llevar al sistema al óptimo elegido. Por ello, la presencia de fallos del mercado justifica la intervención gubernamental, en el sentido de que el Estado recupera la legitimidad científica para intervenir en el sistema económico, tanto desde la óptica de la distribución como desde la propia eficiencia. De esta forma, en la postguerra mundial:

... parecía existir, tanto en el mundo académico como en la praxis política, un cierto consenso sobre el papel del Estado en las economías industriales desarrolladas. La magnum opus de R.A. Musgrave (1959) sintetiza el papel económico del Estado, instrumentalizado primordialmente a través de la política presupuestaria, en las tres funciones clásicas: 'asignación', 'distribución', y 'estabilización'. La primera función comprende aquellas políticas que tienen como objetivo la utilización eficiente de los recursos y la producción de bienes colectivos que el mercado es incapaz de producir o suministrar eficientemente. [La función de distribución se ocupa de aquellos ajustes de la distribución de la renta y la riqueza] 
para asegurar la conformidad con lo que la sociedad considera un estado 'correcto' o 'justo' (Roque, 2004: 220).

La última función hace referencia a la política presupuestaria como un medio de mantener alto el empleo, un grado razonable de estabilidad del nivel de los precios y una tasa adecuada de crecimiento, teniendo en cuenta los efectos sobre el comercio y la balanza de pagos.

La existencia de límites del mercado llevó a la constitución de la economía del bienestar, que rechazaba tanto la aplicación del análisis económico neoclásico a realidades distintas como la pretensión neoclásica de que las relaciones entre países siempre generan beneficios mutuos. El rechazo de la economía neoclásica fue lo que distinguió sobre todo a los primeros especialistas en desarrollo tras la Segunda Guerra Mundial (Böcker, 2005). Se puede nombrar entre ellos a Hirschman (1961 y 1973), Rosenstein-Rodan (1963), Perroux (1984), Lewis (1963), Rostow (1973), Nurkse (1960 y 1968) y Prebisch (1964 y 1987). Por su parte, Prebisch sentará las bases de lo que se denominará posteriormente estructuralismo latinoamericano. Para estos autores, una condición necesaria para el bienestar económico es abordar el problema de la distribución o equidad, sino el análisis económico se hace espurio. Así para Pigou (1974), el Estado tiene dos tareas añadidas a las fijadas por Adam Smith: intervenir en el sistema económico para primero, mejorar su eficiencia y segundo, mejorar el bienestar mediante la distribución a favor de los pobres. Pero para ello era necesario el crecimiento y la industrialización, lo que supuso poner a ambos en el centro del desarrollo.

Existían dentro de la economía del desarrollo dos posturas respecto al crecimiento (Brunet y Böcker, 2007): la Teoría del Desarrollo y los Rendimientos Crecientes, y la Teoría del Crecimiento Equilibrado. En la Teoría del Desarrollo y los Rendimientos Crecientes, se destacan Hirschman (1961), Myrdall (1957) y Perroux (1984). La postura de esta teoría respecto al crecimiento es que se trataba de un crecimiento basado en la concentración de la inversión en unos sectores determinados, aquellos que son más aptos para fomentar el crecimiento de otros sectores de la economía, es decir, los que tienen mayores efectos de arrastre. Por tal motivo, este crecimiento es denominado crecimiento desequilibrado. En teoría, los sectores más eficaces al respecto son los de bienes intermedios, ya que ejercen a la vez efectos de arrastre hacia delante (en las industrias de bienes de consumo) y hacia atrás (en las industrias de bienes de capital).

La insistencia de la Teoría del Desarrollo en los polos de crecimiento, las inversiones arrastradoras o las industrias organizadoras, reflejaba la afirmación de Hirschman, según la cual, el desarrollo es una secuencia de desequilibrios productivos y espaciales. Esta afirmación sobre el desarrollo como crecimiento geográficamente desequilibrado orientará las políticas de polos de crecimiento o de "descentralización concentrada": el desarrollo debía hacerse a través de la atracción de grandes empresas y la promoción de actividades industriales en un número reducido de ciudades de tamaño medio. Esta concepción del desarrollo se construyó alrededor de la idea de que los mecanismos de acumulación de capital conducen a una dinámica de desarrollo desigual en el territorio. En un grupo, relativamente reducido de ciudades, se articularían los procesos de crecimiento y cambio estructural de una economía. El elemento central de los procesos de crecimiento es la empresa matriz, que con su capacidad innovadora $y$ su liderazgo ejerce un efecto impulsor sobre las demás empresas. Su localización, en un territorio concreto, genera desigualdades productivas y espaciales, así como, promueve el crecimiento. El crecimiento es por tanto, jerarquizado. Las decisiones de inversión:

... de la empresa matriz (en bienes de equipo, tecnología, organización) ejercen un efecto inducido en las empresas que se relacionan con ella, que toman, a su vez, sus propias decisiones de inversión. Las decisiones de la empresa matriz fomentan la difusión de las innovaciones, que se transmiten por la red de empresas dependientes de forma horizontal y vertical. El crecimiento sería, por lo tanto, siempre polarizado (Vázquez, 1999: 316). 
Para esta teoría, el tipo de desarrollo como secuencia de desequilibrios se debía a la imposibilidad de un crecimiento diferente al existente en las economías subdesarrolladas, por la insuficiencia de capacidad inversora, la escasez de capacidad empresarial y de gestión o las restricciones del presupuesto estatal. Por ello, estas economías podrían crecer a partir del aprovechamiento de las ventajas de la especialización internacional $y$ al superior aprovechamiento de los efectos de arrastre. Algunas críticas hechas a esta interpretación por los representantes del crecimiento equilibrado, son las siguientes: la concentración de la capacidad inversora en solo unos pocos sectores industriales puede suponer sobre especialización, lo que impide la diversificación del tejido industrial y puede hacer que los efectos de arrastre se vean exportados hacia otros países. Además, hay dificultades para identificar los sectores con mayores efectos de arrastre, $y$ la agricultura queda marginada, en teoría, por sus muy escasos efectos de arrastre. Sin embargo, Hirschman expone que:

... aquellos que destacan la importancia del crecimiento equilibrado han hecho una contribución importante al reconocer que hay diferentes actividades económicas y de inversión que dependen unas de otras, pero de ello han sacado la conclusión demasiado fácil de que todas estas actividades interrelacionadas deben efectuarse simultáneamente (1961: 12).

Hirschman estaba en desacuerdo con la teoría del crecimiento equilibrado, pues no veía factible que diferentes sectores de una economía en desarrollo pudieran crecer al mismo ritmo para evitar dificultades de oferta. Por esta razón, dice Hirschman que tal teoría ha necesitado anexarse a la Teoría del Desarrollo de Rosenstein-Rodan. Por este motivo su crítica principal es que la teoría fracasa como teoría del desarrollo:

Se supone que el desarrollo significa el proceso mediante el cual un tipo de economía se convierte en algún otro tipo más avanzado. Pero, en la teoría del crecimiento equilibrado, un proceso de este tipo no puede presentarse ya que le es difícil visualizar el rompimiento del 'equilibrio del subdesarrollo' en cualquiera de sus puntos. [Más adelante, señala que] uno de los aspectos más curiosos de la teoría es la forma en que combina una actitud derrotista sobre las aptitudes de las economías subdesarrolladas con las expectativas enteramente irreales sobre sus capacidades creadoras (1961: 60-61).

La aplicación del crecimiento equilibrado requeriría precisamente de montos enormes de aquellas capacidades cuya oferta es muy limitada en los países subdesarrollados; es decir, generalmente, no existen los recursos iniciales necesarios para que aparezcan cambios simultáneos en muchos sectores.

La segunda postura en la Economía del desarrollo (la del crecimiento equilibrado) estaba representada fundamentalmente por Rosenstein-Rodan (1963), Nurkse (1960) y Lewis (1963). Estos autores sostenían que el crecimiento es el resultado de una distribución o reparto equitativo de la inversión entre los distintos sectores de la industria de bienes de consumo para sacar provecho de las interdependencias entre ellos y para acelerar el crecimiento. De este modo, proponían la necesidad de aumentar el tamaño del mercado, la posibilidad de obtener economías de escala y el aprovechamiento de las economías externas pecuniarias y de las complementariedades de la demanda.

Este planteamiento dio lugar a procesos de crecimiento basados en la sustitución de importaciones, lo que se ha conocido como la estrategia de industrialización por sustitución de importaciones. Estrategia ampliamente utilizada en América Latina en los años 50 y 60, la cual se conoce como desarrollismo. Por lo tanto, se adecuaba a la Teoría del Crecimiento Equilibrado de Nurkse $y$ a la del gran salto de Rosenstein-Rodan, que preconizaban una industrialización multisectorial, organizada a través del Estado, con el fin de conseguir un umbral crítico. Estas medidas fueron el centro de las objeciones de los teóricos de la dependencia que les acusaban sobre todo de hacer el 
juego a las burguesías nacionales. Por su parte, la teoría neoclásica cuestionaba al desarrollismo, que no se podía renunciar a todo tipo de especialización internacional, pues ser autárquico es menos eficiente que importar determinados productos. Además, esto implicaría disponer de recursos financieros abundantes y perfectamente divisibles, lo cual se pone en duda, dada la poca capacidad privada y del Estado para encarar dichas inversiones.

La teoría del crecimiento dualista y la acumulación de capital también surgió en el seno de la postura del crecimiento equilibrado. Esta teoría tuvo como principal representante a Lewis (1963), quien afirmaba que el factor esencial para el desarrollo económico es la acumulación de capital, junto con los conocimientos y las destrezas aplicadas al proceso productivo. El modelo de Lewis se basaba en el dualismo y planteaba que el objetivo del desarrollo era el de utilizar en el sector moderno, la mano de obra excedente en el sector tradicional, formado por un alto número de subempleados agrícolas, con muy baja o incluso nula, productividad marginal del trabajo. Para Lewis, la falta de crecimiento de los países subdesarrollados no se debía a la incapacidad de ahorro de los sectores populares, sino a la estrechez del sector moderno y capitalista de la economía. Sin embargo, Lewis mantenía al ahorro en su papel tradicional como agente principal del crecimiento y como deseaba relacionar al crecimiento con el tamaño del sector moderno y no con el de toda la economía, llegaba a la conclusión de que solo los capitalistas ahorran (o que sus ahorros son los que cuen$\tan )$. Asimismo, Lewis pensaba, como otros economistas del desarrollo, que la desigualdad aumentaría en las primeras fases del desarro1lo, pues es la desigualdad que acompaña a los beneficios, la que favorece la formación de capital. Como el hecho central del desarrollo es la acumulación rápida de capital, Lewis se centraba en el problema de la capacidad de ahorro e inversión de una economía.

Resumiendo, tanto para los partidarios del crecimiento equilibrado como para los del desequilibrado, aplicar de manera concertada el capital dentro del sector industrial exigía la intervención estatal. Para distribuir convenientemente la inversión entre todos los sectores de bienes de consumo (Rosenstein-Rodan o Nurkse) o para concentrarla en un número reducido de sectores industriales, los que tuviesen más efectos de arrastre (Hirschman o Perroux) o simplemente, para superar el callejón sin salida del círculo vicioso de la pobreza (Nurkse), no se podía confiar en el libre funcionamiento de las fuerzas del mercado. No obstante, también se criticó la pretensión de imponer en los países en desarrollo las políticas keynesianas (Perroux).

\section{CONTRAREVOLUCIÓN NEOCLÁSICA Y NEOLIBERALISMO}

El crecimiento que caracterizó la denominada "edad de oro" del capitalismo a partir de la segunda posguerra mundial, se vio bruscamente alterado al inicio de los años 70 (Hobsbawm, 2001). Esto fue determinante para que se impusiera el dominio de la economía neoclásica hasta nuestros días. El PIB disminuyó por primera vez desde el final de la Segunda Guerra Mundial, pero también la inflación duplicó su ritmo de crecimiento y los tipos de interés nominales y las tasas de paro crecieron con fuerza. El modelo de producción industrial de postguerra entró en crisis debido a la desaceleración económica, que a su vez generó cambios en la política fiscal y de redistribución de la renta. El cambio esencial en la fiscalidad fue la tendencia a dar mayor peso a la eficiencia frente a la equidad. Esto se tradujo en reformas fiscales basadas en tres principios:

1) Reducir los incentivos perversos de la imposición directa anterior.

2) Potenciar el principio de equidad horizontal - tratar igual a los iguales - en detrimento de la vertical - tratar de forma diferente a los distintos.

3) Simplificar administrativamente los impuestos.

Estos cambios fueron la manifestación de las nuevas políticas estructurales de oferta orientadas a reducir la excesiva intervención y regulación estatal, lo que se plasmó en la aceptación generalizada del principio de subsidiariedad. 
Bajo el principio de subsidiariedad quedó establecido que el sector público solo debía hacer aquello que demostrara hacer mejor que la iniciativa privada, lo que determinó, según Segura (2005), los siguientes efectos:

1) El primer efecto fue el proceso de liberalización de los mercados, que en muchos casos pasaron a ser de ámbito mundial. Ejemplos significativos de este proceso son la reducción de barreras arancelarias y otros obstáculos al comercio mundial, los avances en la construcción de áreas supranacionales como la Unión Europea, las reformas de los mercados de trabajo $y$ la liberalización de los mercados de capitales y de divisas.

2) El segundo efecto fue el cambio en las políticas regulatorias. Frente a la regulación y la proliferación de toscos instrumentos de intervención cuantitativa que interferían en el funcionamiento de los mercados, las nuevas prácticas regulatorias se fueron haciendo más sensibles a generar incentivos compatibles con un comportamiento eficiente de los mercados.

3) El tercer efecto fue el intenso proceso de privatización de empresas públicas $y$ de externalización de diversos servicios públicos.

En este contexto, las ideas originales de Keynes (1985) fueron sometidas a una metamorfosis que dejó de lado un conjunto de elementos centrales que son imprescindibles para comprender algunas causas de la crisis actual, diseñar políticas para impulsar la actividad económica y regular los mercados financieros. Una de esas ideas esenciales de Keynes era que el nivel de actividad está determinado por el gasto, por la demanda efectiva. Este autor había invertido la causalidad vigente en las teorías ortodoxas de su época otorgando un lugar predominante a la demanda efectiva. En su reemplazo se instaló la reducción del déficit fiscal mediante el ajuste como mecanismo para reactivar la actividad económica.

El principio de subsidiariedad se basaba en la creencia neoclásica de que ya no existían las condiciones necesarias para una expansión rentable a partir de políticas keynesianas. Esto llevó a economistas y gobiernos al convencimiento de que el objetivo de la política económica debería concentrarse en favorecer el funcionamiento eficiente de los mercados $y$ crear las condiciones de estabilidad que favorecieran el crecimiento sostenido de la economía (Lal, 1983). Esto trajo consigo que las políticas de oferta se apoyaran en los siguientes dos principios contrarios a la política económica keynesiana:

1) Las políticas económicas debían perseguir como objetivo fundamental la estabilidad, ser neutrales y sustituir la discrecionalidad por reglas de comportamiento estrictas y conocidas por los agentes económicos que de esta forma, verían reducida su incertidumbre y podrían incorporarlas en sus decisiones económicas.

2) La influencia del sector público en los procesos de asignación de recursos debía instrumentarse mediante un adecuado sistema de incentivos y no por medio de la intervención directa en los procesos productivos, dando mayor protagonismo a los mercados y eliminando en lo posible los obstáculos para su funcionamiento flexible.

A partir de estos dos principios, la teoría positiva del sector público o teoría de los fallos del Estado sostiene que los fallos del mercado serían una condición necesaria, pero no suficiente, para justificar la intervención estatal. Desde esta perspectiva, la desaceleración económica se debió a fallos del Estado; es decir, a las reglas constitucionales que gobiernan los usos políticos de la sociedad y el funcionamiento del propio sistema económico y fiscal. Así, se trataría de reglas que son restricciones jurídicas y sociales que es preciso remover.

La teoría positiva del sector público se va a colocar, por otra parte, en la vanguardia de una nueva campaña moral, según la cual, la justicia social era un espejismo. Esta campaña, que lideró en la década de los 80, la denominada "Nueva Derecha", planteó que el Estado del 
Bienestar era necesariamente paternalista, no respetaba a los individuos como agentes pensantes $y$ decisores, $y$ se apoyaba en el uso de la coerción ilegítima. Con total independencia de sus fallos prácticos, para la "Nueva Derecha", el Estado del Bienestar era moralmente insolvente.

La hegemonía de la economía neoclásica obedeció en gran parte al descrédito del análisis keynesiano, a la crisis de la economía del desarrollo y a la decadencia de las perspectivas neomarxistas. Desde entonces, el pensamiento neoclásico tiene una gran influencia en las ideas y programas de los principales organismos internacionales, cuyas críticas al intervencionismo gubernamental $y$ el culto a las virtudes del libre mercado procuraron una redefinición del Estado en todos sus frentes. Ello quedó reflejado en la década de los 80, con las denominadas políticas de estabilización seguidas de una política de ajuste estructural, y en la década de los 90, en el llamado "Consenso de Washington" (Brunet y Böcker, 2007 y 2013; Böcker, 2013). "Consenso" que pretendía dar respuesta a la crisis de la deuda externa que afloró a partir del 15 de agosto de 1982, cuando México anunció la imposibilidad de cumplir con los pagos de su primer paquete de medidas de ajuste estructural para salir de la crisis.

El diagnóstico ofrecido desde el "Consenso" era que se trataba de una crisis provocada por el crecimiento del Estado, la ineficiencia de las empresas públicas, el excesivo proteccionismo y el populismo económico que imposibilitaban el control del déficit público. Este conjunto de medidas estaban orientadas en la primera etapa de estabilización de la economía a corregir desequilibrios macroeconómicos como la inflación y el déficit exterior, $y$ en la segunda etapa de ajuste estructural, a generar un modelo de desarrollo orientado al mercado. Así, este tipo de medidas se convirtieron en el modelo estándar del "Consenso de Washington", que ensalzaba el desarrollo gradual, continuo $y$ armónico, asimismo, el libre juego de las fuerzas de oferta y demanda (la lógica perfecta del mercado) (Vázquez, 1990).

Este "Consenso", con la participación de los bancos comerciales internacionales $y$ de los gobiernos de los países más ricos, bajo el liderazgo de los Estados Unidos, supuso el desmantelamiento de las barreras a la libertad de comercio y a los flujos de capital, exponiendo las economías nacionales a la disciplina de los mercados, bajo la suposición de que mediante la aplicación de la libertad de comercio al desarrollo se reduciría la pobreza al aumentar los índices de crecimiento e introduciendo el capitalismo moderno en las regiones más pobres del planeta.

Además, el "Consenso de Washington" englobaba la austeridad y limitación del gasto público para evitar la inflación, las reducciones fiscales de las rentas altas para aumentar las inversiones, los tipos de cambio débiles para favorecer la competitividad, la libertad de los intercambios comerciales, las privatizaciones de las empresas nacionales y del patrimonio de los Estados, la supresión de subvenciones principalmente agrícolas y sobre todo, la desregulación mediante la eliminación de reglamentaciones $y$ controles que fueran contrarios a la iniciativa económica (Bulmer-Thomas, 1996).

Estos aspectos van a configurar el proceso denominado globalismo (Beck, 1998) y que califica una integración económica mundial bajo el dominio de una práctica e ideología económica, social y política neoliberal o neoclásica. Práctica e ideología que incorpora lo que el Grupo de Lisboa (1995) llamó "evangelio de la competencia". Un evangelio para el que la competencia es la respuesta a casi todos los problemas económicos. Si empeora el problema del desempleo, entonces es necesario aumentar la competitividad. Si existe un problema creciente de pobreza en algunos países, entonces hay que ser más competitivo. Asimismo, la educación y la capacitación deben orientarse más a la panacea de la competencia. Como resultado:

...las sociedades se ven progresivamente implicadas en una batalla económica despiadada. Hallamos cada vez más informes con títulos tales como 'Ganar en la economía mundial', y el culto a la competencia dispone incluso de su propio instrumento 'científico', el llamado 'índice de competitividad mundial', publicado anualmente por el Word 
Economic Forum, mediante el cual se evalúa la competitividad de los países de manera similar a la que la Asociación de Tenis Internacional califica a sus jugadores profesionales (Emmerij, 1998:15).

El culto a la competencia aduce como legitimación que el libre comercio conduciría a los países a un óptimo crecimiento y bienestar. Bajo este culto laten los siguientes postulados de la teoría neoclásica del desarrollo (Hunt, 1989):

1) La creencia en la desigualdad económica como incentivo humano.

2) La creencia de que las operaciones del mercado sin intervención gubernamental maximizan la eficiencia y el bienestar.

3) La creencia en el propio beneficio mutuo del comercio internacional.

4) La creencia en la importancia del sistema de precios como referente de información fundamental para la asignación de recursos.

Sin embargo, este culto y estos supuestos trajeron a partir de los años 90, una "nueva era de las desigualdades" (Fitoussi y Ronsanvallon, 1996), que se profundizó a partir de la crisis desatada en 2008.

\section{CONCLUSIONES}

La persistente crisis global puso nuevamente en evidencia las falencias del pensamiento económico hegemónico. De hecho, uno de los principales aportes de este artículo es intentar clarificar histórica y conceptualmente las políticas públicas y sus fundamentos teóricos en el contexto actual.

La incapacidad de las teorías ortodoxas para abordar las causas de la crisis y la incapacidad de las políticas de austeridad para salir de esta, imponen la necesidad de superar el modelo económico, social y político del neoliberalismo. Si el liberalismo económico de Adam Smith (1990) ofrecía una alternativa capitalista al Estado absolutista $y$ a la sociedad feudal, el neoliberalismo actual es una reacción conservadora contra el Estado keynesiano y la sociedad del bienestar, tal y como se explicó en las páginas anteriores. Las políticas de austeridad:

... están dirigidas a los recursos y capacidades del Estado y a los salarios de los trabajadores y no a las transferencias multimillonarias que se han hecho a los grupos financieros. Con ello se sustrajo de la economía real enormes recursos que minan el bienestar de la población y la demanda agregada en tanto palanca de crecimiento económico y generación de empleo (Böcker, 2013: 1).

De este modo, los países entran en números rojos y en lugar de recaudar más a través de impuestos a las altas rentas $y$ al sector financiero, deben hacer frente a los condicionamientos de ajuste del Fondo Monetario Internacional y del Banco Central Europeo, así como a las crecientes tasas de interés para contraer nueva deuda.

De hecho, las políticas neoliberales aplicadas recientemente por los países europeos demostraron que no han sido patrimonio exclusivo de la derecha: la ortodoxia se convirtió en una trampa para los partidos socialdemócratas europeos, ya que carecieron de voluntad política para sostener su histórica agenda progresista $y$ por ello, fueron desalojados del poder.

Todo ello explica en gran parte que Europa no solo esté estancada económicamente desde hace un año, sino que según datos del Eurostat, el $24,2 \%$ de la población europea desde 2011, está en riesgo de caer en situación de pobreza o de exclusión social, esto es un total de 120 millones de europeos (Serrano, 2012). O cambian las cosas y los nuevos "sures" del norte actúan como tantos ejemplos en América Latina o el subdesarrollo en territorio desarrollado será irreversible.

\section{BIBLIOGRAFÍA}

LIBROS

Alonso, Luis. La era del consumo. Madrid: Siglo XXI, 2005.

Arrighi, Giovanni. El largo siglo $x x$ : dinero $y$ poder en los orígenes de nuestra época. Madrid: Akal, 1999. 
Arrow, Kenneth J. Limits of organization. Nueva York: Norton, 1974.

Beck, Ullrich. ¿Qué es la globalización? Falacias del globalismo, respuestas a la globalización. Barcelona: Paidós, 1998.

Brunet, Ignasi y Böcker Zavaro, Rafael. Desarrollo, industria y empresa. Madrid: Tecnos, 2007.

Brunet, Ignasi y Böcker Zavaro, Rafael. Capitalismo global: aspectos sociológicos. Madrid: Grupo 5, 2013.

Bulmer-Thomas, Victor. The New Economic Model in Latin America and its impact on income distribution and poverty. Londres: Mac Millan, 1996.

Bustelo, Pablo. Teorías contemporáneas del desarrollo económico. Madrid: Síntesis, 1998.

Comín, Francisco. "La segunda industrialización en el marco de la primera globalización". Historia económica mundial. Siglos $X-X X$. Francisco Comín, Mauro Hernández y Enrique Llopis (eds.). Barcelona: Crítica, 2005.

Emmerij, Louis. "Teoría y práctica del desarrollo: ensayo introductorio $y$ conclusiones de política". El desarrollo económico y social en los umbrales del siglo XXI. Louis Emmerij y José Núñez del Arco (comps.). Washington: Banco Interamericano de Desarrollo, 1998.

Fitoussi, Jean-Paul y Rosanvallon, Pierre. Le nouvel âge des inégalités. París: Editions du Seuil, 1996.

Grupo de Lisboa. Limits to competition. Nueva York: Massachusetts Institute of Technology - MIT Press, 1995.

Hirschman, Albert. La estructura del desarrollo económico. México DF: Fondo de Cultura Económica, 1961.

Hirschman, Albert. Desarrollo y América Latina: obstinación por la esperanza. México DF: Fondo de Cultura Económica, 1973.

Hobsbawm, Eric. Historia del siglo $X X$. Barcelona: Crítica, 2001.

Hunt, Diana. Economic theories of development. An analysis of competing paradigms. Londres: Harvester Wheatsheaf, 1989.
Keynes, John Maynard. Teoría general de la ocupación, el interés y el dinero. México DF: Fondo de Cultura Económica, 1985.

Kicillof, Axel. Fundamentos de la Teoría General. Las consecuencias teóricas de Lord Keynes. Buenos Aires: EUdEBA, 2008.

Lal, Deepak. The poverty of development economics. West Sussex: Institute of Development Economic Affairs, 1983.

Lewis, W. Arthur. Teoría del desarrollo económico. México DF: Fondo de Cultura Económica, 1963.

Méndez, Ricardo y Caravaca, Inmaculada. Organización industrial y territorio. Madrid: Editorial Síntesis, 1996.

Miedes, Blanca. "Problemas económicos y Ciencia Económica. Hacia un enfoque renovado en la economía". Economía mundial. Manuela de Paz Bañez (coord.). Madrid: Pirámide, 1998.

Myrdal, Gunnar. The self organizing economy. Cambridge: Blackwell, 1957.

Nurkse, Ragnar. Problemas de formación de capital en los países insuficientemente desarrollados. México DF: Fondo de Cultura Económica, 1960.

Nurkse, Ragnar. Comercio internacional y desarrollo económico. Buenos Aires: Amorrortu, 1968.

Perroux, François. El desarrollo y la nueva concepción de la dinámica económica. París: UNEsCo, 1984.

Pigou, Arthur. Memorials of Alfred Marshall. Nueva York: Kelley and Milham, 1974.

Prebisch, Raúl. Hacia una dinámica del desarrollo latinoamericano. México DF: Fondo de Cultura Económica, 1964.

Prebisch, Raúl. Capitalismo periférico, crisis y transformación. México DF: Fondo de Cultura Económica, 1987.

Rojo, Luis Ángel. Ensayos de economía y pensamiento económico. San Vicente del Raspeig, España: Publicaciones de la Universidad de Alicante, 2006.

Roque, Sergio. La naturaleza económica del Estado: una revisión crítica del análisis económico de la política. Las Palmas de Gran Canaria, España: Universidad de Las Palmas de Gran Canaria, 2004. 
Rosenstein-Rodan, Perroux. "Notas sobre una teoría del gran salto". El desarrollo económico y América Latina, Howard Ellis (ed.). México DF: Macmillan-Fondo de Cultura Económica, 1963.

Rostow, Walt Whitman. Las etapas del desarrollo económico. Un manifiesto no comunista. México DF: Fondo de Cultura Económica, 1973.

Segura, Julio. "La economía mundial entre 1973 y el siglo xxI: el final del crecimiento dorado". Historia económica mundial Siglos $X-X X$. Francisco Comín, Mauro Hernández y Enrique Llopis (eds.). Barcelona: Crítica, 2005.

Smith, Adam. Investigación sobre la naturaleza y causas de la riqueza de las naciones. México D.F: Fondo de Cultura Económica, 1990.

Vázquez, Antonio. "Gran empresa y desarrollo endógeno. ¿Convergencia de las estrategias de las empresas y territorios ante el desafío de la competencia?". Latin American Adjustment. John Williamson (ed.). Washington DC: Institute of International Economics, 1990.
REVISTAS

Donoso, Vicente. "Globalización: una perspectiva norte-sur". Gaceta Sindical Reflexión y Debate. 2 de junio de 2002.

Serrano Mancilla, Alfredo. "El subdesarrollo del desarrollo en el Viejo Continente". Página 12.4 de diciembre de 2012.

TESIS

Böcker Zavaro, Rafael. "Desarrollo, planificación estratégica y corporativismo local: el caso de Mar de Plata, Argentina". [Tesis Doctoral]. Universitat Rovira i Virgili, 2005.

\section{TEXTOS ELECTRÓNICOS}

Böcker Zavaro, Rafael. "Europa ante la encrucijada neoliberal". [Ponencia en línea]. 2013. En: <http://www.fes-web. org/congresos/11/ponencias/405/> [consultado el 8 de mayo de 2013].

Fecha de ingreso: 04/04/2013 Fecha de aprobación: 18/10/2013 
